Check for updates

Cite this: RSC Adv., 2018, 8, 7235

Received 16th December 2017 Accepted 7th February 2018

DOI: 10.1039/c7ra13387a

rsc.li/rsc-advances

\section{Influence of a Lewis acid and a Brønsted acid on the conversion of microcrystalline cellulose into 5- hydroxymethylfurfural in a single-phase reaction system of water and 1,2-dimethoxyethane}

\begin{abstract}
Yuan Zhao, (D) Shurong Wang, (D) * Haizhou Lin, Jingping Chen and Hao Xu
5-Hydroxymethylfurfural (HMF) is a typical dehydration product of $\mathrm{C} 6$ carbohydrates, and it can be converted into a series of chemicals and liquid fuels. In this study, an advanced low-boiling single-phase reaction system consisting of water and 1,2-dimethoxyethane (DMOE) was proposed for the production of $\mathrm{HMF}$ from microcrystalline cellulose (MCC). $\mathrm{AlCl}_{3}$ and $\mathrm{H}_{3} \mathrm{PO}_{4}$ were selected as the Lewis acidic catalyst and Brønsted acidic catalyst, respectively, and the influence of these two catalysts on the conversion behavior of MCC was studied. The results showed that MCC could be selectively converted into HMF or levulinic acid (LA) by altering the solvent composition. As for the composition of the catalyst, high $\mathrm{AlCl}_{3}$ content favored the generation of $\mathrm{HMF}$, whereas high $\mathrm{H}_{3} \mathrm{PO}_{4}$ content could decrease the HMF yield and promote the formation of glucose and fructose. The highest HMF yield of $49.42 \%$ was obtained at an $\mathrm{AlCl}_{3}-\mathrm{H}_{3} \mathrm{PO}_{4}$ ratio of $1: 0.8$. GC-MS analysis suggested that much $\mathrm{MCC}$ was transformed into furans and cyclopentenones in the presence of $\mathrm{AlCl}_{3}$, while anhydrosugars tended to be generated with a high $\mathrm{H}_{3} \mathrm{PO}_{4}$ proportion in the catalyst. Besides, FTIR analysis of the insoluble humin formed during MCC conversion indicated that $\mathrm{AlCl}_{3}$ could also facilitate the depolymerization of MCC.
\end{abstract}

\section{Introduction}

In recent years, along with the rapid economic expansion all over the world, there is an increasing demand for energy and chemicals in human society. ${ }^{\mathbf{1}, 2}$ Furan compounds, which can be directly derived from biomass carbohydrates through dehydration, are very important precursors for many value-added chemicals and fuels. ${ }^{3,4}$ For example, a single dehydration process of C6 carbohydrates can form 5-hydroxymethylfurfural (HMF), which is an important biorefinery building block since it is crucial to the synthesis of a series of valuable chemical intermediates and liquid fuels like 2,5-furan dicarboxylic acid (FDCA), 2,5-dimethyl furan (DMF) and levulinic acid (LA)., FDCA-derived polymer polyethylene furanoate (PEF) is used in the production of bottles, fibers and films; DMF can be an additive in current petroleum fuels; GVL is a hydrogenation product of LA and can be upgraded to fuel additives and jet fuels. ${ }^{7,8}$ Therefore, it is of great importance to develop efficient and economical reaction systems for the production of HMF.

Lignocellulosic biomass is one of the most promising feedstocks for HMF production as it can be easily obtained from nature. Especially, cellulose is a kind of macromolecular polysaccharide that is the most widely distributed and the most

State Key Laboratory of Clean Energy Utilization, Zhejiang University, Zheda Road 38 , Hangzhou 310027, China. E-mail: srwang@zju.edu.cn; Tel: +8657187952066 abundant on the earth, and it account for almost $50 \mathrm{wt} \%$ in biomass. ${ }^{9}$ Cellulose consists of a linear chain of several hundred to many thousands of $\beta-1,4$-glycosidic bond linked glucose units. Recent efforts have been primarily focused on the conversion of glucose and fructose to HMF in order to reveal the mechanisms involved in the production of HMF. ${ }^{\mathbf{1 0 1 1}}$ However, in a practical point of view, cellulose is a much more reasonable feedstock for large-scale HMF production, even if it still faces several challenges such as its firm crystal structure and multiple side reactions. ${ }^{\mathbf{1 2}}$

In a common conversion process from cellulose to HMF, cellulose is firstly hydrolyzed to form oligosaccharides and glucose, which was usually catalyzed by a Brønsted acid catalyst; then, with the aid of a Lewis acid catalyst, the isomerization of glucose occurs to form fructose, and fructose will undergo consecutive dehydration reactions to form HMF. ${ }^{\mathbf{1 3}}$ Actually, glucose can also be directly dehydrated to generate HMF, but it is usually more difficult for this route to occur than the isomerization-dehydration route owing to the different conformer distribution of glucose and fructose solution. ${ }^{14,15}$ Consequently, it is a commonly recognized strategy to combine Lewis acid and Brønsted acid in the catalytic conversion of $\mathrm{C} 6$ carbohydrates to HMF. In addition to the catalyst, a good reaction medium is also an important aspect for efficient HMF production, since it could affect the distribution of intermediates and the selectivity of different products. ${ }^{16,17}$ 
Table 1 presents an overview of recent progress in C6 carbohydrates dehydration for HMF production in the presence of different solvents and catalysts. The synergistic effect of Lewis acidic catalyst and Brønsted acidic catalyst was reported to be pivotal for efficient production of HMF and its important derivative LA from C6 carbohydrates. ${ }^{18-22}$ Zhang et al. found that Lewis acidic $\mathrm{AlCl}_{3}$ and Brønsted acidic maleic acid could couple with each other to form catalytic complexes, which were able to favor the hydride shift in glucose for isomerization leading to enhanced reaction rates and HMF selectivity. ${ }^{22}$ In general, Lewis acid could promote the isomerization reaction from glucose, while Brønsted acid is significant for the hydrolyzation of polysaccharides and the dehydration of monosaccharides. ${ }^{19}$ $\mathrm{AlCl}_{3}$ was reported to be an attractive Lewis acidic catalyst among the metal chlorides for the conversion of glucose to $\mathrm{HMF}^{21,22}$ and it also has great potential for commercial HMF production due to its low toxicity and low cost. ${ }^{23}$ Water is the most recommended solvent for its availability, but actually it was usually combined with polar aprotic solvent so as to get rid of side reactions (i.e., HMF rehydration). ${ }^{11}$ In recent years ionic liquids have been a focus of attention because it could overcome the physical and biochemical barriers of the cellulose hydrolysis reaction. ${ }^{24}$ Although the above solvent systems exhibited satisfying performance for HMF formation, product isolation could be a challenge for the downstream chemical processing. For instance, biphasic solvents required a large sum of organic extractant, and ionic liquids were expensive and hard to be evaporated out of the solution. ${ }^{6}$ Hence a green solvent with low boiling point was demanded to establish a single-phase reaction system in large-scale HMF production. ${ }^{25}$

Herein, a single-phase reaction system composed of renewable 1,2-dimethoxyethane (DMOE), water, $\mathrm{AlCl}_{3}$ and $\mathrm{H}_{3} \mathrm{PO}_{4}$ was proposed for HMF production from microcrystalline cellulose (MCC). DMOE is a renewable organic solvent that can be synthesized from bio-based ethylene glycol, ${ }^{33}$ and it is a polar aprotic solvent miscible with water. DMOE has low boiling point $\left(84.6{ }^{\circ} \mathrm{C}\right)$ that is lower than commonly used polar aprotic solvents like dimethylformamide (DMF, $153{ }^{\circ} \mathrm{C}$ ), dimethyl sulfoxide (DMSO, $189{ }^{\circ} \mathrm{C}$ ) and $\gamma$-valerolactone (GVL, $207{ }^{\circ} \mathrm{C}$ ), and therefore it requires a small amount of energy for separation through distillation. Moreover, studies have shown that polar aprotic solvent could improve HMF yields significantly, because of fewer side reactions that occurred in non-aqueous solvent. ${ }^{34} \mathrm{AlCl}_{3}$ and $\mathrm{H}_{3} \mathrm{PO}_{4}$ were chosen as the Lewis acidic catalyst and the Brønsted acidic catalyst, respectively. The effect of water-DMOE ratio on product selectivity was investigated, followed by the influence of reaction temperature and time. Then the catalytic effect of Lewis acid and Brønsted acid was studied in depth by adjusting their mole ratio. The liquid-phase products and the solid insoluble humins formed at different $\mathrm{AlCl}_{3}-\mathrm{H}_{3} \mathrm{PO}_{4}$ mole ratios were analyzed by gas chromatographymass spectrometry (GC-MS) and Fourier Transform Infrared Spectroscopy (FTIR), respectively.

\section{Experimental section}

\subsection{Materials}

Glucose, fructose, microcrystalline cellulose (MCC), HMF, LA and DMOE were purchased from Aladdin Industrial Corporation (Shanghai, China). $\mathrm{AlCl}_{3} \cdot 6 \mathrm{H}_{2} \mathrm{O}$ and $\mathrm{H}_{3} \mathrm{PO}_{4}$ were purchased from Sinopharm Chemical Reagent (Shanghai, China). All chemicals were of analytical grade and were directly used without purification.

\subsection{Procedure for conversion of cellulose to HMF}

In a typical reaction process, a mixture of cellulose $(10 \mathrm{mmol}$ (1.8 g) based on monosaccharide units), solvent (water-DMOE at a specified volume ratio; $50 \mathrm{~mL})$ and catalysts $\left(\mathrm{AlCl}_{3}\right.$ and $\mathrm{H}_{3} \mathrm{PO}_{4}$ ) were placed in the Parr reactor (Parr Instruments, Moline, IL, USA; $100 \mathrm{~mL}$ ). For different catalyst compositions, the mass of $\mathrm{AlCl}_{3}$ ranged from 0 to $0.133 \mathrm{~g}$ ( 0 to $1 \mathrm{mmol}$ ), while the mass of $\mathrm{H}_{3} \mathrm{PO}_{4}$ ranged from 0 to $0.098 \mathrm{~g}$ ( 0 to $1 \mathrm{mmol}$ ). The reactions were carried out under mechanical agitation in a $\mathrm{N}_{2}$ atmosphere, and the stirring rate was maintained at $300 \mathrm{rpm}$. After the preset reaction temperature and time were reached, heating was stopped and the reactor was cooled by airflow. Samples were filtered through a $0.22 \mu \mathrm{m}$ syringe filter prior to high performance liquid chromatography (HPLC) and GC-MS analyses. Each experiment was repeated three times, and the resulting mean value and standard deviation are shown in the figures.

Table 1 C6 carbohydrates dehydration to HMF in acidic reaction systems

\begin{tabular}{|c|c|c|c|c|c|c|}
\hline Reactant & Solvent (additive) & Catalyst & Temp. $\left({ }^{\circ} \mathrm{C}\right)$ & Time (h) & HMF yield (\%) & Ref. \\
\hline Fructose & Water/isopropanol & $\mathrm{CO}_{2}$ & 180 & 2 & 67.1 & 16 \\
\hline Glucose & Water/DMOE & $\mathrm{AlCl}_{3}$ & 150 & 0.75 & 58.5 & 26 \\
\hline Glucose & Water $(\mathrm{NaCl})$ & $\mathrm{AlCl}_{3} / \mathrm{HCl}$ & 170 & 3 & 62.0 & 27 \\
\hline Cellulose & Water/MIBK & LPSnP-1 & 150 & 0.33 & 32.0 & 28 \\
\hline Cellulose & Water/THF (NaCl) & Sn-Mont & 160 & 3 & 39.1 & 29 \\
\hline Cellulose & Water/THF & $\mathrm{NaHSO}_{4} / \mathrm{ZnSO}_{4}$ & 160 & 1 & 53.0 & 31 \\
\hline Cellulose & {$[\mathrm{BMIM}] \mathrm{Cl}$} & $\mathrm{Cr}\left([\mathrm{PSMIM}] \mathrm{HSO}_{4}\right)_{3}$ & 130 & 5 & 53.0 & 32 \\
\hline
\end{tabular}




\subsection{Analytical methods}

The filtered solution was analyzed on a Dionex HPLC system (Dionex, Sunnyvale, CA, USA) equipped with a Bio-Rad Aminex HPX-87H column (Bio-Red, Hercules, CA, USA) and an RI 2000 refractive index detector (Schambeck SFD GmbH, Bad Honnef, Germany). $\mathrm{H}_{2} \mathrm{SO}_{4}$ solution ( $\mathrm{pH} 2.5$ ) was used as the mobile phase, and its flow rate and the corresponding column temperature were kept at $0.6 \mathrm{~mL} \min ^{-1}$ and $60{ }^{\circ} \mathrm{C}$, respectively. The concentrations of glucose, fructose, LA, formic acid (FA) and HMF were determined by reference to standard calibration curves. The yields of hexoses (glucose and fructose), LA, FA and HMF were calculated as follows:

$$
\text { Hexose yield }=\frac{\text { moles of hexose formed }}{\text { moles of hexose units in cellulose }} \times 100 \%
$$$$
\text { LA yield }=\frac{\text { moles of LA formed }}{\text { moles of hexose units in cellulose }} \times 100 \%
$$$$
\text { FA yield }=\frac{\text { moles of FA formed }}{\text { moles of hexose units in cellulose }} \times 100 \%
$$

$$
\mathrm{HMF} \text { yield }=\frac{\text { moles of HMF formed }}{\text { moles of hexose units in cellulose }} \times 100 \%
$$

In order to understand the process of glucose decomposition, the filtered samples were also analyzed by GC-MS (Thermo Scientific, Trace DSQII) equipped with a DB-wax capillary column $(30 \mathrm{~m} \times 0.25 \mathrm{~mm} \times 0.25 \mathrm{~mm})$. Helium $(99.999 \%)$ at

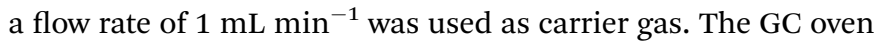
temperature was programmed to increase from $40{ }^{\circ} \mathrm{C}(1 \mathrm{~min})$ to $240{ }^{\circ} \mathrm{C}(20 \mathrm{~min})$ at $8{ }^{\circ} \mathrm{C} \mathrm{min}^{-1}$ heating rate. The MS detector was operated in electron ionization (EI) mode $(70 \mathrm{eV})$ with a scan range of $m / z 35-450$. All detected chemicals were identified by comparison with the NIST (National Institute of Standards) MS library.

\subsection{Humins isolation and analyses}

Insoluble polymeric humins from cellulose conversion process were obtained as follows. After reaction, the samples were filtered through a $0.22 \mu \mathrm{m}$ organic filter membrane to obtain the insoluble residue. The remaining solid residues after washing with water were dried at $105{ }^{\circ} \mathrm{C}$ for $2 \mathrm{~h}$, and the dry solid was considered as insoluble humins. FTIR spectra of the humins were recorded from 400 to $4000 \mathrm{~cm}^{-1}$ at resolution of $4 \mathrm{~cm}^{-1}$ on a Nicolet 5700 FTIR spectrometer by averaging 36 scans. The yield of humin was calculated as the mass of cellulose divided by the mass of humins.

\section{Results and discussion}

\subsection{Effect of solvent composition}

At first, the mixtures of water-DMOE (7:1) and $\mathrm{AlCl}_{3} / \mathrm{H}_{3} \mathrm{PO}_{4}$ catalysts before and after heating at $180{ }^{\circ} \mathrm{C}$ for $2 \mathrm{~h}$ were analyzed by GC-MS. The results showed no decomposition behavior of DMOE, and therefore DMOE was stable in the reaction system. As described in Fig. 1, the solvent composition has a great influence on the typical product distribution from cellulose. In pure water solvent, the main product formed from cellulose were LA with a high yield of $39.01 \%$ and FA with a yield of $14.94 \%$, while the yield of glucose, fructose and HMF remained at pretty low levels $(<0.5 \%)$. Theoretically, LA would be produced in a $1: 1$ ratio with formic acid from HMF rehydration. However, this ratio could be greater than, equal to or less than 1:1 in experiments under different conditions. ${ }^{35}$ For instance, Asghari et al. found that when catalyzed by hydrochloric acid, FA could decompose faster than LA after they were generated from HMF rehydration, leading to a much higher yield of LA than that of FA. ${ }^{36}$ However, when the organic solvent DMOE was gradually added into the solution until the DMOEwater ratio reached $7: 1$, the yield of LA and FA showed a steep drop while the yield of HMF rose rapidly to $48.27 \%$. Besides, both the yield of glucose and fructose increased at first and decreased thereafter, and their maximum yields of $8.20 \%$ and $5.35 \%$ were arrived at a DMOE-water ratio of $1: 1$, respectively. The results suggested significant effects of solvent on the degradation route of cellulose when catalyzed by $\mathrm{H}_{3} \mathrm{PO}_{4}$ and $\mathrm{AlCl}_{3}$.

In pure water solvent, cellulose could be hydrolyzed adequately with the help of Brønsted acid to generate glucose, and subsequently the glucose was catalyzed by Lewis acid to undergo isomerization reaction. Afterwards the formed fructose was dehydrated to form HMF in the presence of Brønsted acid, and HMF was easily rehydrated in the water-rich environment, resulting in the formation of LA and FA. Thus, the synergistic catalytic effect of Lewis acid and Brønsted acid in aqueous solvent could be utilized to transform cellulose or glucose into LA. For example, Yang et al. achieved a LA yield of $49.8 \%$ in a reaction system containing $\mathrm{H}_{3} \mathrm{PO}_{4}$ and $\mathrm{CrCl}_{3} \cdot{ }^{37}$ Nemoto et al. used $\mathrm{H}_{3} \mathrm{PO}_{4}$ and $\mathrm{AlCl}_{3}$ as catalysts to convert cellulose into LA and a maximum LA yield of $50 \%$ was obtained. ${ }^{38}$ Along with the

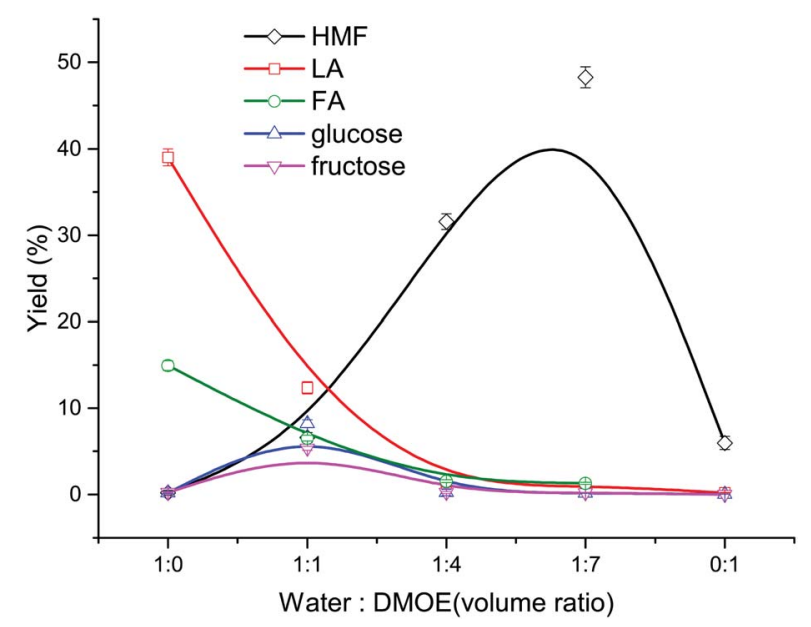

Fig. 1 Effect of solvent composition on the product distribution from cellulose conversion $\left(180{ }^{\circ} \mathrm{C}, 120 \mathrm{~min}, 0.02 \mathrm{M} \mathrm{AlCl}_{3}, 0.02 \mathrm{M} \mathrm{H}_{3} \mathrm{PO}_{4}\right.$, $36 \mathrm{mg} \mathrm{mL}^{-1}$ cellulose). 
increasing proportion of DMOE and the decreasing water content, the generated HMF could be protected by the increasing non-aqueous solvent (DMOE) concentration and the hydrogen-bond interaction between DMOE and HMF. ${ }^{26}$ In this way the formation of LA and FA was inhibited and the reactive HMF could be preserved.

In pure organic solvent, all of these products were hardly formed, and the yield of HMF was as low as 5.96\% (not shown in Fig. 1). It was extremely difficult for cellulose to be hydrolyzed towards monosaccharides without water, and therefore further reactions would hardly occur. In spite of this, there was still a little HMF that could be detected, which might come from other reaction paths. Weingarten et al. reported the production of HMF from cellulose in polar aprotic solvents without the presence of water, and they deemed that the cellulose firstly degraded to form levoglucosan, which was then dehydrated to generate HMF. ${ }^{30}$

\subsection{Effect of reaction temperature and time}

As shown in Fig. 2a, when the reaction went up from $170{ }^{\circ} \mathrm{C}$ to $180{ }^{\circ} \mathrm{C}$, the yield of HMF grew from $33.62 \%$ to $48.27 \%$, correspondingly. Nevertheless, when the reaction temperature

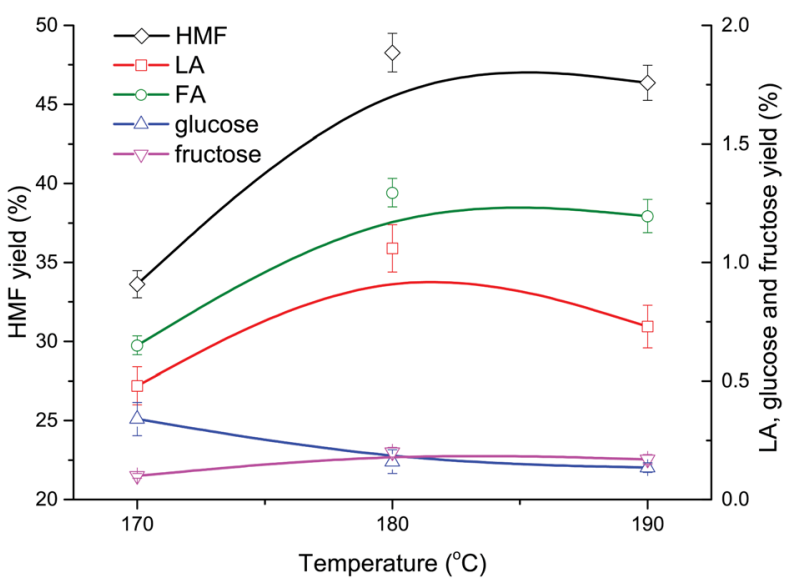

(a)

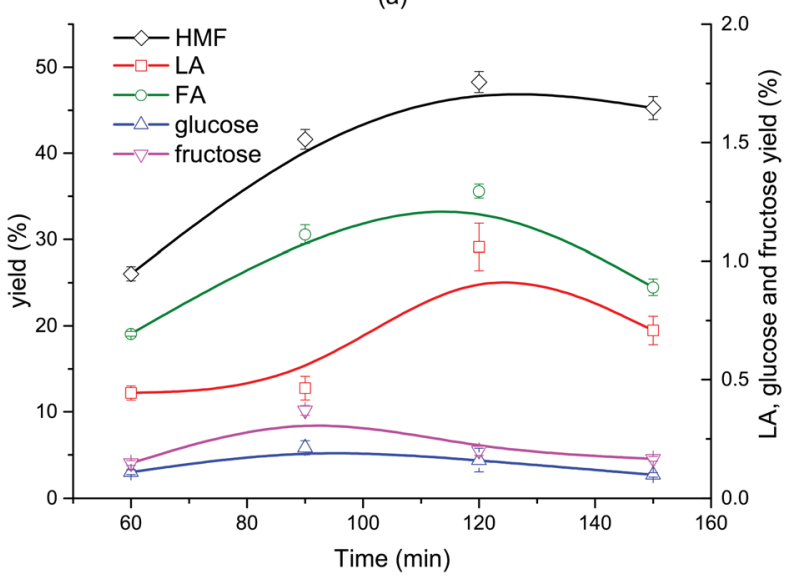

(b)

Fig. 2 Effect of reaction temperature (a) and time (b) on the product distribution from cellulose conversion (DMOE-water (7: 1), $120 \mathrm{~min}$ (a), $180{ }^{\circ} \mathrm{C}$ (b), $0.02 \mathrm{M} \mathrm{AlCl}_{3}, 0.02 \mathrm{M} \mathrm{H}_{3} \mathrm{PO}_{4}, 36 \mathrm{mg} \mathrm{mL}^{-1}$ cellulose). further increased to $190{ }^{\circ} \mathrm{C}$, the HMF yield slightly dropped to $46.35 \%$. The yields of glucose and fructose were both lower than $1.5 \%$, indicating a nearly complete conversion of the monosaccharides coming from cellulose hydrolysis. Little LA and FA were formed $(<2 \%)$ due to the impeded secondary reactions involving HMF in the presence of DMOE. The generation trend of LA with rising temperature coincided with that of HMF, and its yield reached a maximum value at $180{ }^{\circ} \mathrm{C}$. At higher reaction temperatures LA and HMF could become much more reactive to undergo side reactions (i.e., condensation), which might be the cause of the fluctuant tendency of HMF and LA in Fig. 2a. The yield of FA at different temperatures followed the same tendency as that of LA. As for the monosaccharides, the glucose yield showed a decline with increasing temperature, while the yield of fructose remained almost unchanged. The product distribution from cellulose at different reaction time was depicted in Fig. 2b. It was obvious that the generation of HMF, LA and FA followed an increasing tendency with the reaction time going by, and both of them reached the peak values at $120 \mathrm{~min}$. After $120 \mathrm{~min}$ the yield of HMF began to fall because HMF was easily rehydrated to form byproducts like formic acid and humins. ${ }^{39}$ Similarly, LA and FA could also undergo some side reactions (fragmentation and polymerization) in acidic reaction conditions. ${ }^{40}$ The yields of glucose and fructose were below $0.5 \%$ and showed a slow fluctuation with the highest yields achieved at $90 \mathrm{~min}$.

\subsection{Effect of Lewis acid and Brønsted acid on liquid-phase product}

After cellulose was hydrolyzed to form glucose, the synergistic catalytic effect between Lewis acid and Brønsted acid is required for an efficient production of HMF from glucose, as shown in Fig. 3.

In the conversion process of cellulose, the synergistic catalytic effect between Lewis acid and Brønsted acid is required for an efficient production of HMF. The product distribution from cellulose conversion with different Lewis acid $\left(\mathrm{AlCl}_{3}\right)$-Brønsted acid $\left(\mathrm{H}_{3} \mathrm{PO}_{4}\right)$ ratios is presented in Fig. 4 . When only $\mathrm{AlCl}_{3}$ was added, the HMF yield reached up to $40.24 \%$, indicating that $\mathrm{AlCl}_{3}$ had good catalytic performance on the HMF production from cellulose in the proposed water-DMOE solvent system. After $\mathrm{H}_{3} \mathrm{PO}_{4}$ was gradually added to the solution, the HMF yield showed an ascent at first, and it arrived at the highest value of $49.42 \%$ when the $\mathrm{AlCl}_{3}-\mathrm{H}_{3} \mathrm{PO}_{4}$ mole ratio was $1: 0.8$. The main reason was that $\mathrm{H}_{3} \mathrm{PO}_{4}$ could promote the hydrolysis process of cellulose to generate monosaccharide (glucose). In this way, the following isomerization reaction of glucose catalyzed by $\mathrm{AlCl}_{3}$ would be facilitated. When the $\mathrm{AlCl}_{3}-\mathrm{H}_{3} \mathrm{PO}_{4}$ mole ratio decreased to $1: 1$, the HMF yield dropped slightly to $48.27 \%$. Noticeably, as the proportion of $\mathrm{AlCl}_{3}$ further declined, the HMF yield fell considerably to $36.73 \%, 27.33 \%$ and $13.46 \%$ at the $\mathrm{AlCl}_{3}-\mathrm{H}_{3} \mathrm{PO}_{4}$ ratio of $0.8: 1,0.5: 1$ and $0.1: 1$, respectively. It could be concluded that $\mathrm{H}_{3} \mathrm{PO}_{4}$ had few catalytic effects on the formation of $\mathrm{HMF}$, because $\mathrm{H}_{3} \mathrm{PO}_{4}$ mainly behaved as a Brønsted acid to provide hydrogen ions for the hydrolysis and dehydration reactions. Although $\mathrm{PO}_{4}{ }^{3-}$ could be recognized as 


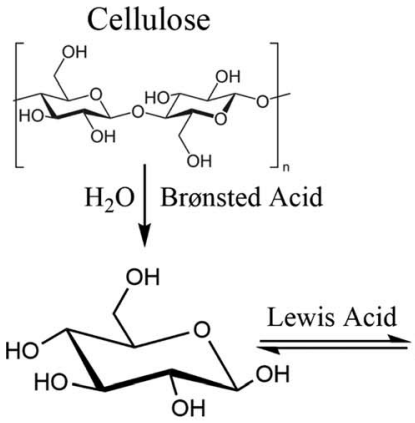

Glucose

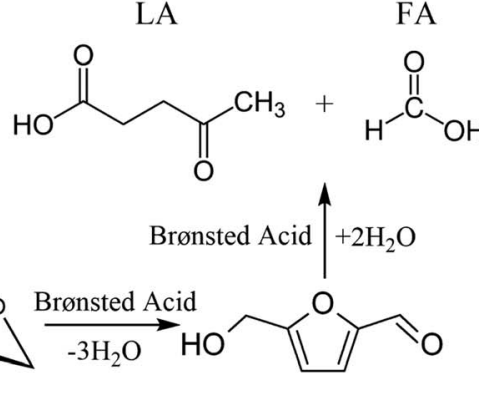

Fructose

HMF

Fig. 3 Transformation of cellulose to HMF catalyzed by Lewis acid and Brønsted acid.

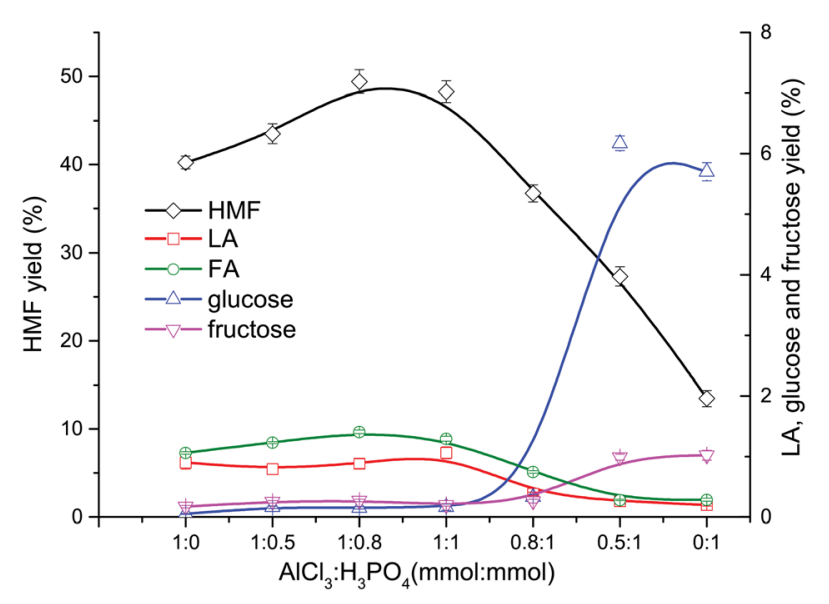

Fig. 4 Effect of $\mathrm{AlCl}_{3}-\mathrm{H}_{3} \mathrm{PO}_{4}$ mole ratio on the product distribution from cellulose conversion (DMOE-water $(7: 1), 180{ }^{\circ} \mathrm{C}, 120 \mathrm{~min}$, $36 \mathrm{mg} \mathrm{mL}^{-1}$ cellulose).

a conjugate base and facilitate the isomerization reaction of glucose to generate fructose, its Lewis acidity was actually much lower than $\mathrm{AlCl}_{3}$, leading to decreased HMF yield without the presence of $\mathrm{AlCl}_{3}$. Yin et al. also reported unsatisfactory HMF yield of $20.72 \%$ from cellulose with only a Brønsted acidic catalyst (hydrochloric acid). ${ }^{41}$ Consequently, for the purpose of high-efficiency production of HMF from cellulose, the Lewis acid-Brønsted acid ratio needed to be optimized to take full advantage of their synergistic effect.

As for the formation of LA and FA, it can be seen from Fig. 4 that the yields of LA and FA were both around 1\% when the $\mathrm{AlCl}_{3}$ concentration was not less than $\mathrm{H}_{3} \mathrm{PO}_{4}$. As the share of $\mathrm{AlCl}_{3}$ decreased, the yields of LA and FA also dropped slowly, which could be attributed to the lower HMF yield in the presence of excess $\mathrm{H}_{3} \mathrm{PO}_{4}$.

Obviously, the yields of glucose and fructose were pretty low $(<0.5 \%)$ when the $\mathrm{AlCl}_{3}-\mathrm{H}_{3} \mathrm{PO}_{4}$ mole ratio was higher than $1: 1$, and at these ratios fructose was always more than glucose. This suggested that most of the glucose formed from cellulose hydrolyzation was converted into fructose with Lewis acidic $\mathrm{AlCl}_{3}$ as the catalyst, and then the fructose was dehydrated to generate $\mathrm{HMF}$. As the $\mathrm{AlCl}_{3}-\mathrm{H}_{3} \mathrm{PO}_{4}$ mole ratio decrease to $0.5: 1$, the yields of glucose and fructose rose significantly to
$6.17 \%$ and $1.02 \%$, respectively, resulting in much more unreacted glucose caused by insufficient $\mathrm{AlCl}_{3}$. When no $\mathrm{AlCl}_{3}$ existed, the yields of glucose and fructose reached $5.70 \%$ and $0.99 \%$, respectively, and the corresponding HMF yield was as low as $13.46 \%$. The decreased yield of glucose from $6.17 \%$ to $5.70 \%$ could be explained by the enhanced dehydration reaction towards anhydrosugars when catalyzed solely by $\mathrm{H}_{3} \mathrm{PO}_{4}$, which was evidenced by the following GC-MS analysis. Besides, glucose might also undergo a variety of acid-catalyzed side reactions to generate undesired products such as humins, which led to its consumption. ${ }^{26}$

In order to provide a deeper insight into the catalytic mechanism of Lewis acid and Brønsted in the water-DMOE solvent system, typical product distribution in the liquid phase at different $\mathrm{AlCl}_{3}-\mathrm{H}_{3} \mathrm{PO}_{4}$ mole ratio was analyzed by GC-MS. The products formed from the catalytic conversion of cellulose were mainly divided into four categories, namely oxygenated aliphatics, furans, cyclopenten-1-ones and anhydrosugars. The distribution variation of these chemical families at different $\mathrm{AlCl}_{3}-\mathrm{H}_{3} \mathrm{PO}_{4}$ mole ratios is shown in Fig. 5 .

As for the oxygenated aliphatics, besides LA and formic acid, they mainly consisted of hydroxyacetones and

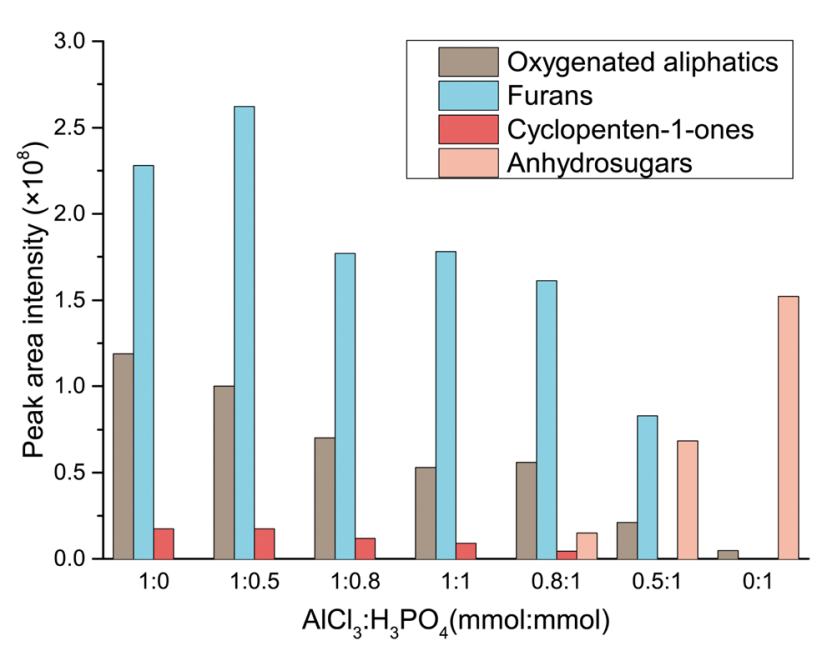

Fig. 5 Effect of $\mathrm{AlCl}_{3}-\mathrm{H}_{3} \mathrm{PO}_{4}$ mole ratio on the product distribution of chemical families from cellulose conversion (HMF, LA, glucose and fructose are not depicted). 


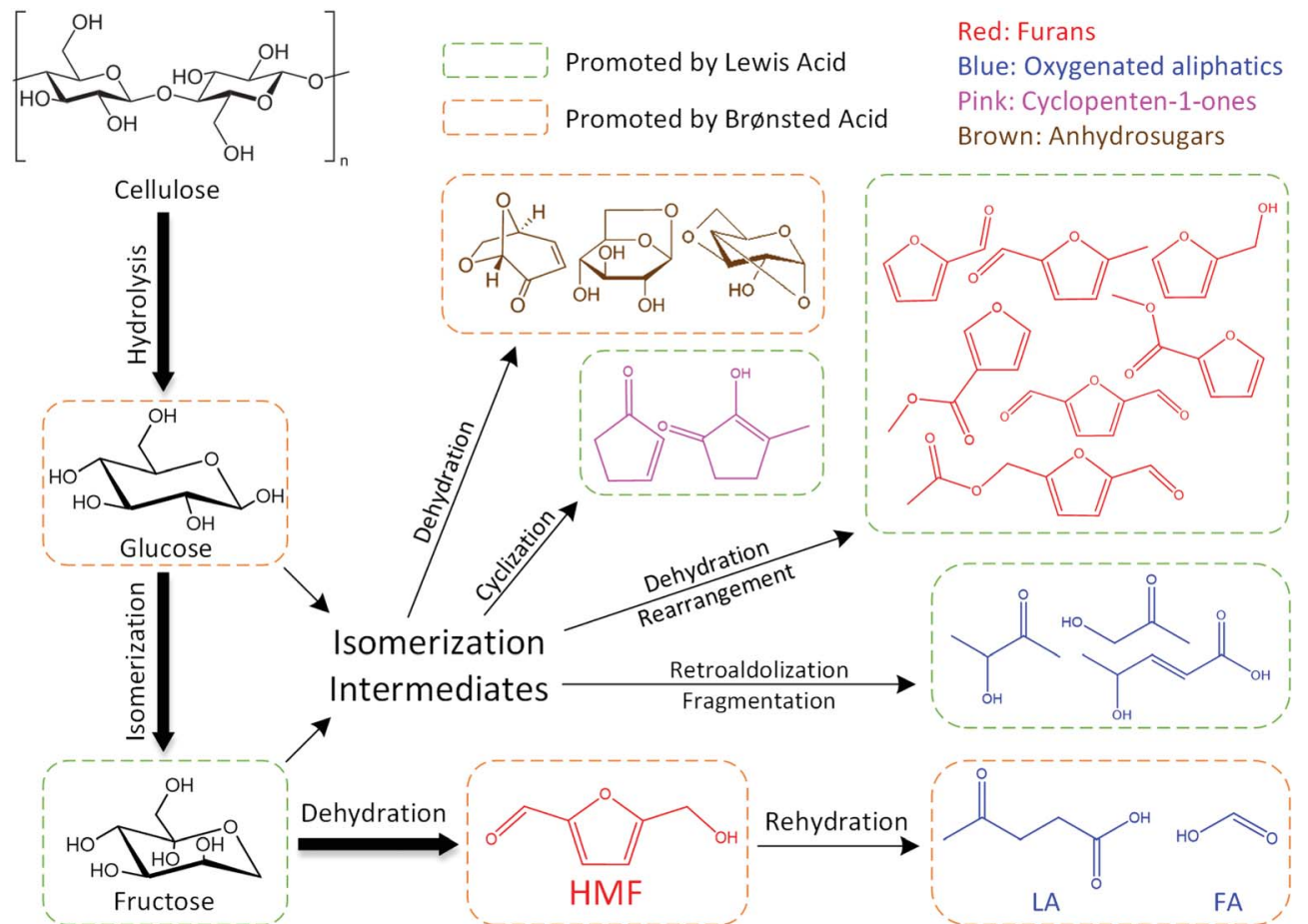

Fig. 6 Liquid-phase products formation pathways for cellulose conversion in water-DMOE solvent reaction system.

hydroxybutanones, which came from the retroaldolization of the intermediates or the fragmentation of acyclic intermediates. ${ }^{42-44}$ As the $\mathrm{AlCl}_{3}-\mathrm{H}_{3} \mathrm{PO}_{4}$ mole ratio decreased, the generation of oxygenated aliphatics was inhibited, suggesting a more profound effect of Lewis acid on the breakage of the carbon chain. Furans were the primary products from cellulose degradation, and they covered a wide range of species including HMF, furfural, 5-methylfurfural, 2,5-diformylfuran, furfuryl alcohol and 5-acetoxymethyl-2-furaldehyde. This chemical family was mainly generated by the dehydration reaction of furanose or the rearrangement of acyclic fragments coming from monosaccharide retroaldolization. In general, it was easy for furans to be formed in the presence of Lewis acid, whereas they presented a lower yield with Brønsted acid as the catalyst. It could be inferred that reaction conditions containing sufficient Lewis acid would promote the generation of furanose, and therefore the formation of furan products was greatly facilitated.

The dominant species of cyclopenten-1-ones were 2-cyclopenten-1-one and methyl cyclopentenolone. This kind of

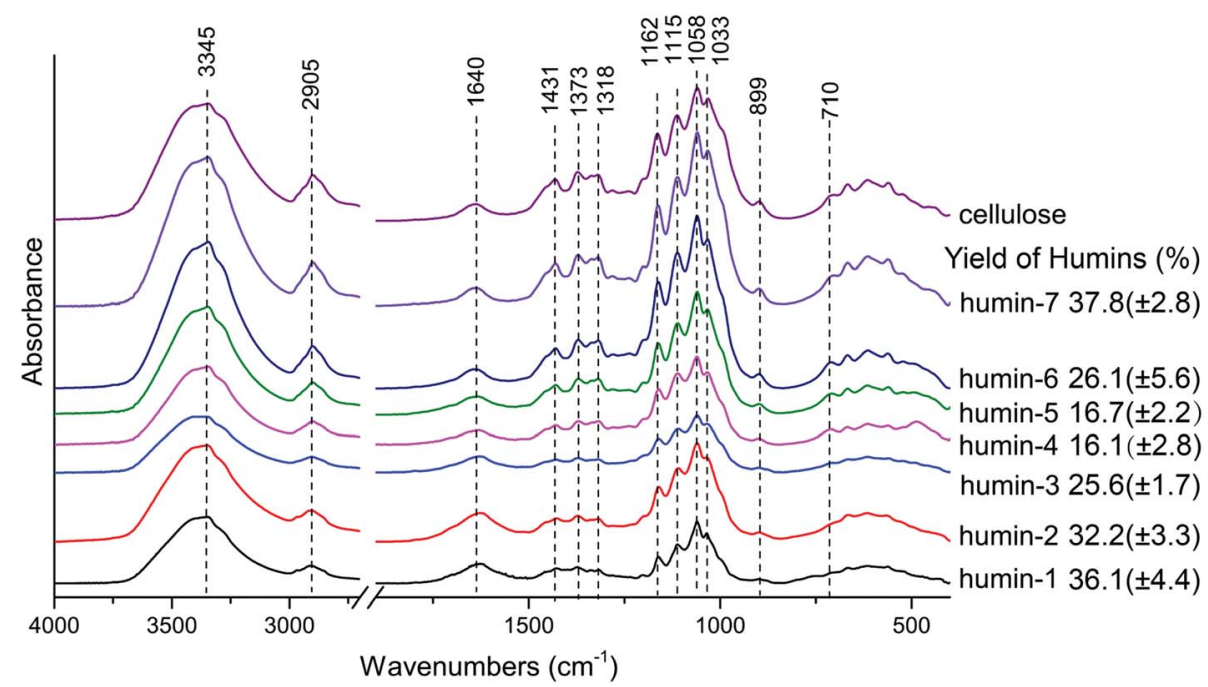

Fig. 7 FTIR spectra and mass yields of insoluble humins formed at different $\mathrm{AlCl}_{3}-\mathrm{H}_{3} \mathrm{PO}_{4}$ mole ratios (humin 1-7 correspond to $\mathrm{AlCl}_{3}-\mathrm{H}_{3} \mathrm{PO} 4$ mole ratios at $1: 0,1: 0.5,1: 0.8,1: 1,0.8: 1,0.5: 1,0: 1$, respectively). 
product with 5-carbon rings might have been produced by cyclization of chain intermediates containing multifunctional groups. Similar to the furans, the generation of cyclopenten-1ones would be favored at high $\mathrm{AlCl}_{3}-\mathrm{H}_{3} \mathrm{PO}_{4}$ mole ratios, while they barely formed with single $\mathrm{H}_{3} \mathrm{PO}_{4}$ catalyst. The anhydrosugars mainly include levoglucosan, levoglucosenone, 1,4:3,6-dianhydro- $d$-glucopyranose and oligosaccharides. These sugars came from the Brønsted acid-catalyzed dehydration of monosaccharides to which cellulose was hydrolyzed. Hence a large amount of anhydrosugars were produced when the reaction was solely catalyzed by $\mathrm{H}_{3} \mathrm{PO}_{4}$, while their yields decreased sharply with the addition of $\mathrm{AlCl}_{3}$. Fig. 6 describes the reaction pathways involving the formation of liquid-phase products from cellulose. However, the related mechanisms are complex and further work is needed for clarification.

\subsection{Effect of Lewis acid and Brønsted acid on insoluble humins}

The mass of insoluble humins were measured. As shown in Fig. 7, it is obvious that the smallest amount of insoluble humins was obtained when the $\mathrm{AlCl}_{3}-\mathrm{H}_{3} \mathrm{PO}_{4}$ mole ratio was $1: 1$. Hence a combination of both Lewis acid and Brønsted acid is required in order to suppressing side reactions that led to humin formation. For the sake of further understanding the effects of catalysts on cellulose conversion when catalyzed by Lewis acid and Brønsted acid in water-DMOE solvent, the insoluble polymer humins were analyzed by FTIR. The FTIR spectra of the humins formed at different $\mathrm{AlCl}_{3}-\mathrm{H}_{3} \mathrm{PO}_{4}$ mole ratios are shown in Fig. 7. Humin 1-7 correspond to $\mathrm{AlCl}_{3}-$ $\mathrm{H}_{3} \mathrm{PO}_{4}$ mole ratios at $1: 0,1: 0.5,1: 0.8,1: 1,0.8: 1,0.5: 1$, $0: 1$, respectively. It could be found that the humin structures at different catalyst ratios were similar to each other. The absorption peaks at $3345 \mathrm{~cm}^{-1}$ and $1318 \mathrm{~cm}^{-1}$ correspond to the stretching and bending of hydroxyl groups, respectively, which widely exist in cellulose structure; the peak at $2905 \mathrm{~cm}^{-1}$ is ascribed to $\mathrm{C}-\mathrm{H}$ stretching, and this structure indicates the existence of methyl and methylene; the absorption at $1640 \mathrm{~cm}^{-1}$ can be attributed to the bond water in samples. ${ }^{45,46}$

The peaks at $1431 \mathrm{~cm}^{-1}$ and $1220 \mathrm{~cm}^{-1}$ come from the bending and stretching of $-\mathrm{CH}_{2}-$ structure in sugar rings, respectively; intensive and complex absorptions appear at 1200$1000 \mathrm{~cm}^{-1}$, and this range mainly correspond to the stretching of the glycosidic linkage $(\mathrm{C}-\mathrm{O}-\mathrm{C})$ and $\mathrm{C}-\mathrm{OH}$ in the sugar rings; ${ }^{45,47,48}$ the signal at $1162 \mathrm{~cm}^{-1}$ is from the $\mathrm{C}-\mathrm{O}-\mathrm{C}$ asymmetric bridge vibration in the $\beta$-glycosidic linkage of cellulose $;^{49,50}$ the absorption at $899 \mathrm{~cm}^{-1}$ corresponds to the $\mathrm{C}_{1}$ group frequency or ring frequency, which is also characteristic of $\beta$ glycosidic linkages between the sugar units; ${ }^{51}$ the absorption band at $710 \mathrm{~cm}^{-1}$ is assigned to $I_{\beta}$ crystalline phase in cellulose. ${ }^{46}$ The above absorption peaks have similar characteristics, and they indicate the fundamental framework of polysaccharides remained in the humins. This might be explained by the lacking of water in the reaction system, leading to insufficient hydrolyzation of cellulose.

In addition, further analysis of the results revealed similarity between the FTIR spectra of cellulose and the humins obtained in $\mathrm{H}_{3} \mathrm{PO}_{4}$-rich conditions (i.e., humin-6 and humin-7), while the spectra of samples from $\mathrm{AlCl}_{3}$-rich conditions (i.e., humin-1, humin-2, humin-3) were different from the spectrum of original cellulose. Especially, the peak intensities of humins from $\mathrm{AlCl}_{3}$-rich conditions at low wavenumbers became much weaker than that of cellulose, which indicated that $\mathrm{AlCl}_{3}$ could destroy the original structure of cellulose to a higher degree than $\mathrm{H}_{3} \mathrm{PO}_{4}$. Similar results were also reported by Ma et al. They studied the effect of $\mathrm{AlCl}_{3}$ and $\mathrm{HCl}$ on cellulose conversion in high temperature liquid water, and $\mathrm{AlCl}_{3}$ was considered to have a more evident impact on the cellulose degradation. ${ }^{52}$ In our previous research, we used glucose as a model compound of cellulose to produce HMF in a similar reaction system of water$\mathrm{DMOE}-\mathrm{AlCl}_{3}$, and the obtained humins were mainly furan polymers from dehydration/condensation reactions of glucose, HMF and intermediates. ${ }^{26}$ Given that the majority of the humins from cellulose in the current work was polysaccharide, they could be recycled and reused in case of unnecessary waste.

\section{Conclusion}

This research focused on the catalytic effects of Lewis acid $\mathrm{AlCl}_{3}$ and Brønsted acid $\mathrm{H}_{3} \mathrm{PO}_{4}$ on the conversion process from cellulose to HMF. Firstly, the influence of solvent composition (water-DMOE ratio) on cellulose conversion catalyzed by both $\mathrm{AlCl}_{3}$ and $\mathrm{H}_{3} \mathrm{PO}_{4}$ was investigated. The results showed that cellulose tended to form LA in pure water solvent, while the yield of HMF significantly increased as the proportion of DMOE went up. In pure DMOE solvent, the reaction pathway of cellulose towards HMF was severely hindered. Consequently, cellulose could be selectively converted into HMF or LA by altering the solvent composition.

The conversion results of cellulose at different $\mathrm{AlCl}_{3}-\mathrm{H}_{3} \mathrm{PO}_{4}$ mole ratios were further analyzed. It was found that $\mathrm{AlCl}_{3}$-rich environment favored the formation of $\mathrm{HMF}$, and the highest $\mathrm{HMF}$ yield $49.42 \%$ was achieved at an $\mathrm{AlCl}_{3}-\mathrm{H}_{3} \mathrm{PO}_{4}$ mole ratio of $1: 0.8$. In $\mathrm{H}_{3} \mathrm{PO}_{4}$-rich conditions, the generation of $\mathrm{HMF}$ was greatly inhibited and more glucose and fructose would be produced. Moreover, the liquid-phase products were analyzed by GC-MS, and they could be mainly separated into oxygenated aliphatics, furans, cyclopenten-1-ones and anhydrosugars. $\mathrm{AlCl}_{3}$ was able to facilitate the formation of furans and cyclopenten-1ones, whereas more anhydrosugars would be produced in the presence of high $\mathrm{H}_{3} \mathrm{PO}_{4}$ content. FTIR analyses showed that some of the original polymer structures in cellulose were preserved in the insoluble humins, and high proportion of $\mathrm{AlCl}_{3}$ in catalysts could noticeably promote the cellulose degradation.

\section{Conflicts of interest}

The authors declare that they have no competing interests.

\section{Acknowledgements}

This work was supported by the National Science Fund for Distinguished Young Scholars (51725603), the National Natural Science Foundation of China (51476142), the National Science 
and Technology Supporting Plan Through Contract (2015BAD15B06), and the Program of Introducing Talents of Discipline to University (B08026).

\section{References}

1 S. Wang, J. Chen, Q. Cai, F. Zhang, Y. Wang, B. Ru and Q. Wang, Int. J. Hydrogen Energy, 2016, 41, 16385-16393.

2 S. Wang, G. Dai, H. Yang and Z. Luo, Prog. Energy Combust. Sci., 2017, 62, 33-86.

3 J. J. Bozell and G. R. Petersen, Green Chem., 2010, 12, 539554.

4 S. Wang, Y. Zhao, H. Lin, J. Chen, L. Zhu and Z. Luo, Green Chem., 2017, 19, 3869-3879.

5 Y. Yang, Q. Liu, D. Li, J. Tan, Q. Zhang, C. Wang and L. Ma, RSC Adv., 2017, 7, 16311-16318.

6 R.-J. van Putten, J. C. van der Waal, E. De Jong, C. B. Rasrendra, H. J. Heeres and J. G. de Vries, Chem. Rev., 2013, 113, 1499-1597.

7 D. M. Alonso, J. Q. Bond and J. A. Dumesic, Green Chem., 2010, 12, 1493-1513.

8 F. H. Isikgor and C. R. Becer, Polym. Chem., 2015, 6, 44974559.

9 S. Wang, G. Dai, B. Ru, Y. Zhao, X. Wang, G. Xiao and Z. Luo, Energy, 2017, 120, 864-871.

10 J. M. R. Gallo, D. M. Alonso, M. A. Mellmer and J. A. Dumesic, Green Chem., 2013, 15, 85-90.

11 A. Mukherjee, M.-J. Dumont and V. Raghavan, Biomass Bioenergy, 2015, 72, 143-183.

12 S. J. Dee and A. T. Bell, ChemSusChem, 2011, 4, 1166-1173.

13 V. Choudhary, S. H. Mushrif, C. Ho, A. Anderko, V. Nikolakis, N. S. Marinkovic, A. I. Frenkel, S. I. Sandler and D. G. Vlachos, J. Am. Chem. Soc., 2013, 135, 3997-4006.

14 B. Kuster, Starch-Stärke, 1990, vol. 42, pp. 314-321.

15 Y. Zhu, J. Zajicek and A. S. Serianni, J. Org. Chem., 2001, 66, 6244-6251.

16 H. Lin, Q. Xiong, Y. Zhao, J. Chen and S. Wang, AIChE J., 2017, 63, 257-265.

17 H. Lin, J. Chen, Y. Zhao and S. Wang, Energy Fuels, 2017, 31, 3929-3934.

18 T. C. Acharjee and Y. Y. Lee, Environ. Prog. Sustainable Energy, 2018, 37, 471-480.

19 T. Zhang, W. Fan, W. Li, Z. Xu, H. Xin, M. Su, Y. Lu and L. Ma, Energy Technol., 2017, 5, 747-755.

20 W. Weiqi and W. Shubin, Chem. Eng. J., 2017, 307, 389-398.

21 C. Wang, L. Zhang, T. Zhou, J. Chen and F. Xu, Sci. Rep., 2017, 7, 40908.

22 X. Zhang, P. Murria, Y. Jiang, W. Xiao, H. I. Kenttämaa, M. M. Abu-Omar and N. S. Mosier, Green Chem., 2016, 18, 5219-5229.

23 M. Wong and A. Bradshaw, New Phytol., 1982, 91, 255-261.

24 C. Li, Q. Wang and Z. K. Zhao, Green Chem., 2008, 10, 177182.

25 S. P. Teong, G. Yi and Y. Zhang, Green Chem., 2014, 16, 20152026.
26 S. Wang, H. Lin, J. Chen, Y. Zhao, B. Ru, K. Qiu and J. Zhou, RSC Adv., 2015, 5, 84014-84021.

27 Y. J. Pagan-Torres, T. Wang, J. M. R. Gallo, B. H. Shanks and J. A. Dumesic, ACS Catal., 2012, 2, 930-934.

28 A. Dutta, D. Gupta, A. K. Patra, B. Saha and A. Bhaumik, ChemSusChem, 2014, 7, 925-933.

29 J. Wang, J. Ren, X. Liu, J. Xi, Q. Xia, Y. Zu, G. Lu and Y. Wang, Green Chem., 2012, 14, 2506-2512.

30 R. Weingarten, A. Rodriguez-Beuerman, F. Cao, J. S. Luterbacher, D. M. Alonso, J. A. Dumesic and G. W. Huber, ChemCatChem, 2014, 6, 2229-2234.

31 N. Shi, Q. Liu, Q. Zhang, T. Wang and L. Ma, Green Chem., 2013, 15, 1967-1974.

32 L. Zhou, R. Liang, Z. Ma, T. Wu and Y. Wu, Bioresour. Technol., 2013, 129, 450-455.

33 B. Kim, C. A. Antonyraj, Y. J. Kim, B. Kim, S. Shin, S. Kim, K.-Y. Lee and J. K. Cho, Ind. Eng. Chem. Res., 2014, 53, 4633-4641.

34 T. Wang, M. W. Nolte and B. H. Shanks, Green Chem., 2014, 16, 548-572.

35 S. Karwa, V. M. Gajiwala, J. Heltzel, S. K. Patil and C. R. Lund, Catal. Today, 2016, 263, 16-21.

36 F. S. Asghari and H. Yoshida, Ind. Eng. Chem. Res., 2007, 46, 7703-7710.

37 F. Yang, J. Fu, J. Mo and X. Lu, Energy Fuels, 2013, 27, 69736978.

38 K. Nemoto, K.-i. Tominaga and K. Sato, Bull. Chem. Soc. Jpn., 2015, 88, 1752-1754.

39 B. F. Kuster, Carbohydr. Res., 1977, 54, 177-183.

40 N. Ya'aini, N. A. S. Amin and S. Endud, Microporous Mesoporous Mater., 2013, 171, 14-23.

41 S. Yin, Y. Pan and Z. Tan, Int. J. Green Energy, 2011, 8, 234247.

42 S. Dutta, S. De and B. Saha, Biomass Bioenergy, 2013, 55, 355369.

43 M. B. Fusaro, V. Chagnault and D. Postel, Carbohydr. Res., 2015, 409, 9-19.

$44 \mathrm{Y} . \mathrm{Yu}$ and H. Wu, Ind. Eng. Chem. Res., 2011, 50, 1050010508.

45 M. Kačuráková, P. S. Belton, R. H. Wilson, J. Hirsch and A. Ebringerová, J. Sci. Food Agric., 1998, 77, 38-44.

46 R. Liu, H. Yu and Y. Huang, Cellulose, 2005, 12, 25-34.

47 M. Kacurakova, P. Capek, V. Sasinkova, N. Wellner and A. Ebringerova, Carbohydr. Polym., 2000, 43, 195-203.

48 X.-F. Sun, R. Sun, P. Fowler and M. S. Baird, J. Agric. Food Chem., 2005, 53, 860-870.

49 J. Bian, F. Peng, X.-P. Peng, X. Xiao, P. Peng, F. Xu and R.-C. Sun, Carbohydr. Polym., 2014, 100, 211-217.

50 J. Široký, R. S. Blackburn, T. Bechtold, J. Taylor and P. White, Cellulose, 2010, 17, 103-115.

51 J. Fang, R. Sun and J. Tomkinson, Cellulose, 2000, 7, 87-107.

52 Y. Ma, W. Ji, X. Zhu, L. Tian and X. Wan, Biomass Bioenergy, 2012, 39, 106-111. 